\title{
A ciência da informação na visão dos professores da ECI/UFMG
}

\author{
Carlos Alberto Ávila Araujo
}

\begin{abstract}
Professor adjunto da Escola de Ciência da Informação da UFMG, atua nas áreas de Estudos de Usuários e Teoria e Epistemologia da Ciência da Informação.
\end{abstract}

Aline Michelle Sima

Graduanda do $7^{\circ}$ período do curso de Biblioteconomia da UFMG

Roger Miranda Guedes

Graduando do $7^{\circ}$ período do curso de Biblioteconomia da UFMG

Karine Souza Resende

Graduanda do $7^{\circ}$ período do curso de Biblioteconomia da UFMG

Este texto apresenta os resultados de uma pesquisa realizada com os professores da Escola de Ciência da Informação da UFMG sobre os seguintes assuntos: a ciência da informação como uma ciência social; a ciência da informação como uma ciência interdisciplinar; a ciência da informação como uma ciência pós-moderna; a natureza da relação entre a ciência da informação e a biblioteconomia. A cada entrevistado solicitou-se, ainda, que indicasse dez autores e dez obras da área de ciência da informação que ele julgasse relevantes.

Palavras-chave: Pesquisa em ciência da informação; Campo da ciência da informação; Estudos em ciência da informação

\section{Information science in the viewpoint of the teachers of ECI/UFMG}

This text presents the results of a research accomplished with the teachers of the School of Information Science of UFMG on the following subjects: information science as a social sciences; information science as an interdisciplinary 
science; information science as a post-modern science; the nature of the relationship between the information science and librarianship. To each interviewee It was requested, still, to each interviewee that indicated ten authors and ten works of the area of information science to judge relevant.

Key-Words: Research in information science; Field of information science; Studies in information science

Recebido em 13.03.2007 Aceito em 26.04.2007

\section{Introdução}

Os estudos que têm a ciência como objeto de pesquisa proliferaram, ao longo do século $\mathrm{XX}$, em diferentes ramos, tais como a sociologia da ciência, a filosofia da ciência, a história da ciência. Em comum, essas várias vertentes perceberam que, tão importante quanto estudar uma disciplina científica do ponto de vista epistemológico é estudá-la do ponto de vista histórico e social, isto é, compreender a atividade científica como um produto social (GRESSLER, 2003), dotada de uma matriz coletiva.

Não que os estudos de natureza estritamente teórica e epistemológica não sejam importantes para descrever um campo científico. Eles apenas não são suficientes, na medida em que o que move uma disciplina científica numa determinada direção, coloca temas e métodos de pesquisa, se relaciona também com fatores humanos, culturais, históricos. A ciência é feita por homens que, além de cientistas, são pessoas engajadas em processos políticos, dotados de valores e ideologias, interesses e desejos.

Diversos autores foram fundamentais nessa reorientação dos estudos. É o caso de Bourdieu, que realiza uma abordagem sociológica da ciência que entende que "o conhecimento científico, enquanto produto, é afetado pelas condições de um contexto específico" (SILVA, 2002, p. 109) ou, em outros termos, que a verdade científica "reside numa espécie particular de condições sociais de produção" (BOURDIEU, 1983, p. 122). Essa compreensão permite entender a ciência como resultado não propriamente de progressos e questões científicas, mas como resultado dos processos de luta, de utilização e busca por recursos e capital simbólico, pela lógica de distinção (instâncias de consagração e de prestígio que se relacionam com o grau de aceitação no campo).

Sem dúvida também Foucault tem imensa relevância nos estudos sobre a ciência. Isso porque o filósofo salienta o fato de que o discurso científico não é formado apenas por ciência propriamente dita (pelas teorias e conceitos científicos), mas por uma quantidade imensa de saberes políticos, administrativos, institucionais, culturais, literários, artísticos, etc. Com isso se abre a possibilidade de análise da ciência para além dos seus próprios critérios de cientificidade, pois são exatamente 
essas condições de cientificidade ou de verdade que vão ser analisadas pelo autor. Em alternativa às categorias de objetividade e verdade, Foucault busca compreender a ciência como locus de luta entre sistemas competitivos, isto é, como um conhecimento que possui um suporte institucional, reforçado por práticas sociais (ALVARENGA, 1998).

Por fim, estão também em destaque atualmente os estudos de laboratório, inspirados nos trabalhos de Latour e Woolgar, entre outros, que analisam a prática cotidiana de produção do fazer científico, numa abordagem de cunho etnográfico, percebendo as várias interações em que se envolvem os cientistas e como são construídos os critérios de pertinência, autoridade, legitimidade, entre outros. No âmbito dos estudos sociológicos sobre a ciência, a proposta de Latour e Woolgar marcam a virada "da macro para a microanálise da ciência" (HOCHMAN, 1994, p. 214).

\section{Desenho da pesquisa}

As idéias apresentadas acima serviram como inspiração para a realização de uma pesquisa cujo objeto de estudo é a Ciência da Informação - CI. Essa pesquisa foi realizada como atividade da disciplina de Teorias da Informação do curso de Biblioteconomia da UFMG. Além de se promover o estudo das teorias, dos conceitos e métodos (um estudo de natureza mais epistemológica), foi proposta pelo professor da disciplina uma pesquisa com professores que atuam na área de $\mathrm{CI}$, de forma a se saber o ponto de vista deles sobre essa ciência, sobre suas origens, características e problemáticas. Dessa forma, buscou-se perceber que tentar entender o que é a CI está diretamente relacionado com a tarefa de buscar a compreensão que dela têm aqueles que a praticam, isto é, os pesquisadores que efetivamente atuam na área de CI.

A relevância de um trabalho como esse se evidencia ainda no caso de uma ciência como a CI, caracterizada por uma falta de consenso em relação à sua identidade, suas fronteiras, seu objeto e seus métodos de pesquisa (ROBREDO, 2003; OLIVEIRA, 2005).

A partir dessa decisão, todos os alunos da disciplina se juntaram na realização de um trabalho de pesquisa que tinha como objetivo entrevistar todos os professores da Escola de Ciência da Informação - ECI - da UFMG. Essa escolha se deu pela possibilidade de realizar as entrevistas pessoalmente, bem como de analisar as respostas dadas por cada professor em face de seu perfil, sua formação e filiação teórica e institucional.

Elaborou-se um roteiro padrão a ser utilizado em todas as entrevistas, e os professores foram divididos em seis grupos. A composição dos grupos se deu da seguinte forma: em primeiro lugar, separou-se os professores que fazem parte da pós-graduação. Estes, todos doutores, foram divididos conforme as três linhas de pesquisa do Programa de Pós-Graduação em Ciência da Informação da UFMG. São elas: Gestão da Informação e do Conhecimento - GIC, que ficou sendo o grupo 1, com seis professores, com áreas de graduação bastante 
diversificadas como engenharia metalúrgica, ciência da computação, administração, artes cênicas, economia, letras, biblioteconomia e psicologia; Informação, Cultura e Sociedade - ICS, que ficou sendo o grupo 2, com seis professoras, sendo três graduadas em biblioteconomia (duas delas também em letras) e as demais em sociologia, serviço social e história; e Organização e Uso da Informação - OUI, que ficou sendo o grupo 3, com cinco professores, dois graduados em engenharia e três em biblioteconomia (um deles também em letras).

Para o agrupamento dos demais professores, adotou-se o seguinte critério: cinco professores, que compõem juntos um grupo de pesquisa cadastrado no CNPq, o GEBE (Grupo de Estudos em Biblioteca Escolar), constituíram o grupo 4. São todos graduados em biblioteconomia com titulações variadas (uma doutoranda, três mestres e uma especialista). Outros quatro professores, todos substitutos na ECI/UFMG, foram agrupados no grupo 5 . Também graduados em áreas distintas (museologia, biblioteconomia, engenharia e administração), possuem titulações variadas (dois doutorandos, um mestre e um graduado). Os demais cinco professores da ECI/UFMG, em sua maioria recentes na escola, fizeram parte do grupo 6. As áreas de graduação destes professores são história, ciência da computação, engenharia civil e biblioteconomia (duas), sendo quatro doutores e uma doutoranda.

Em relação às perguntas a serem exploradas nas entrevistas, buscou-se trabalhar questões que foram tratadas na disciplina e que representam temas ou pontos sobre os quais a área de CI ainda se debate, isto é, sobre os quais ainda não existe um consenso na área. Esses tópicos foram: ser a CI uma ciência social; ser a CI uma ciência interdisciplinar; ser a CI uma ciência pós-moderna. Para cada tópico destes o professor foi solicitado a responder se concordava ou discordava, explicitando seus argumentos. O tópico seguinte foi a relação existente entre a Biblioteconomia e a CI. Os argumentos dados nas respostas dos professores foram agrupados em categorias e contabilizados numa análise geral e específica por grupo.

A seguir, pediu-se a cada professor que apontasse os dez autores mais relevantes entre aqueles pertencentes à área de informação e, por fim, dez trabalhos (livros, artigos ou quaisquer trabalhos científicos) também considerados mais relevantes na área. Foram contabilizados os autores e trabalhos mais citados, no geral e especificado por grupo.

Para a elaboração deste texto, montou-se uma equipe que juntou os resultados de todos os grupos para promover uma análise geral dos dados encontrados. Os resultados deste trabalho geral são apresentados a seguir, de acordo com cada um dos tópicos que fizeram parte da entrevista.

\section{A natureza social da CI}

A CI, assim como outras disciplinas surgidas após a II Guerra, nasce dentro de um contexto histórico caracterizado pela revolução científica e tecnológica (SARACEVIC, 1996). Por seu caráter fortemente influenciado 
pela evolução tecnológica, e pelo contexto de conhecimento estratégico assumido no período da guerra fria, ela acabou encontrando melhor sustentação nas ciências exatas. Capurro (2003) destaca que o primeiro modelo teórico vigente na CI é um modelo físico, adotado a partir da Teoria Matemática de Shannon e Weaver e efetivamente posto em prática com os experimentos de Cranfield na década de 1950. Ellis (1992) destaca a importância destes testes, cujo campo de pesquisa se assemelhava a laboratórios de física e mecânica, como influenciadores de toda uma tradição de pesquisa, sobretudo na área de recuperação da informação.

Na década de 1970, maior atenção passa a ser dada ao usuário e, desta forma, com a inserção de um elemento humano no quadro da pesquisa, a CI passa a dialogar mais com as ciências humanas e sociais. A partir dessa inserção no campo social e levando-se em consideração que se apóia em fundamentos de outras disciplinas, a CI passa a ampliar a conceituação do seu objeto de pesquisa. A informação passa a ser vista especialmente pelo seu caráter social, ganhando sentido quando inserida no contexto humano. Capurro (2003) destaca que, desde a década de 1960, com os trabalhos de Shera e Egan, mas sobretudo após a década de 1990, ganha corpo na CI o "paradigma social", a partir dos trabalhos de Frohmann, Hjorland, Albrechtsen e o próprio Capurro, entre outros.

Em um artigo de 1993, Wersig afirma que a CI é "interdisciplinar por natureza e, orientada à transferência da informação, tem reforçado suas características como ciência social" (ROBREDO, 2003, p. 64). Essa transferência de que fala o autor parece estar explícita no que Miksa (1992) denominou o paradigma da CI, que tem como fenômeno central o movimento da informação em sistemas de comunicação humana (OLIVEIRA, 2005).

É em torno dessa problemática que se situa a caracterização da CI como uma ciência social. No Brasil, ela está formalmente institucionalizada, pelo $\mathrm{CNPq}$, dentro da grande área ciências sociais aplicadas. Contudo, tal decisão não é suficiente para dizer da natureza social da área e, por isso, optou-se por transformar esse tema numa das perguntas feitas aos professores entrevistados.

Sendo feita a análise de respostas dos professores entrevistados quando questionados sobre a natureza social da $\mathrm{CI}$, houve somente um (dos 31 entrevistados) que não considera a CI uma ciência social, alegando que a CI é muito abrangente tendo outras vertentes que não tratam de aspectos sociais.

Entre os que responderam ser a CI uma ciência social, buscou-se trabalhar as justificativas apresentadas em categorias. A maior parte deles $(36,6 \%)$ justifica sua resposta afirmando que o caráter social da CI se deve principalmente pelo seu objeto de estudo, a informação, sendo esta um fenômeno tão abrangente que se envolve com todos os aspectos da vida em sociedade - a CI é uma ciência que busca o papel da informação e do conhecimento no contexto social. A segunda justificativa mais utilizada pelos professores $(26,6 \%)$ diz respeito à relação entre CI e a sociedade. A CI se envolve com a sociedade solucionando os problemas 
informacionais gerados pelas pessoas. Outros quatro entrevistados $(13,3 \%)$ afirmaram que a natureza social da CI se deve ao fato de que o principal foco da CI é lidar com o usuário e com os ambientes nos quais eles se encontram. A quarta resposta mais usada aponta as teorias e práticas das ciências sociais que são utilizadas pela $\mathrm{CI}$, e que, por isso, esta se insere nas ações da área das ciências sociais. Dois professores $(6,6 \%)$ acreditam que toda ciência é (ou deveria ser) social, uma vez que a atividade científica não pode ser dissociada dos contextos sociais nos quais está inserida. Por fim, as respostas de dois entrevistados foram classificadas na categoria Outros. Um deles afirma que a CI é uma ciência social porque tem fundamento teórico de característica pós-moderna e transdisciplinar da década de 1970, e, o outro diz que inúmeros fatores enquadram a CI no campo social. O total de respostas é apresentado a seguir, na TAB. 1:

TABELA 1 - Justificativas dos entrevistados que disseram ser a CI uma ciência social

\begin{tabular}{|c|c|c|c|c|c|c|c|}
\hline \multirow[b]{2}{*}{ Categorias de respostas } & \multicolumn{6}{|c|}{ Grupos } & \multirow{2}{*}{ Total } \\
\hline & 1 & 2 & 3 & 4 & 5 & 6 & \\
\hline \multirow{7}{*}{ 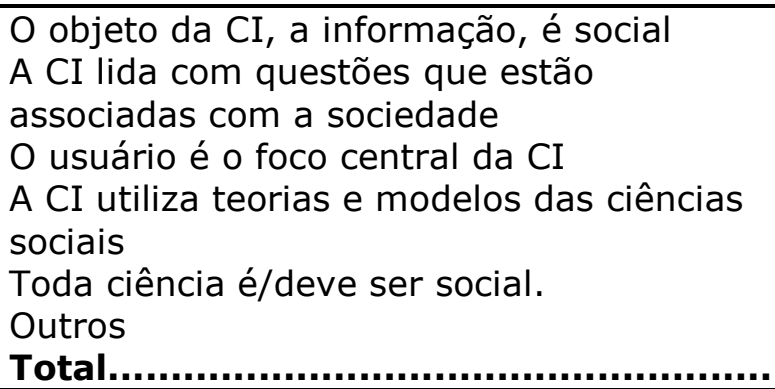 } & 2 & 2 & 1 & 2 & 2 & 2 & 11 \\
\hline & 2 & 1 & 1 & 2 & 1 & 1 & 8 \\
\hline & 2 & - & 2 & - & - & - & 4 \\
\hline & - & 1 & - & 1 & 1 & - & 3 \\
\hline & - & - & 1 & - & - & 1 & 2 \\
\hline & - & 2 & - & - & - & - & 2 \\
\hline & 6 & 6 & 5 & 5 & 4 & 4 & 30 \\
\hline
\end{tabular}

Fonte: Dados da pesquisa.

Pode-se observar pela relação entre a categoria de respostas e os grupos de professores que nenhum dos grupos obteve mais que dois entrevistados com a mesma resposta. Com isso percebe-se a heterogeneidade das perspectivas teóricas dentro de cada grupo e dos professores em geral, embora certas regularidades possam ser vistas como, por exemplo, uma quantidade muito semelhante de respostas relativas à categoria o objeto da CI é social em todos os grupos. É interessante destacar, ainda, a presença maior da relação com o usuário nos grupos 1 e 3 .

\section{A questão da interdisciplinaridade}

A questão relativa à interdisciplinaridade da CI parece ser quase unânime entre os principais estudiosos da área, como também pelos professores entrevistados. O próprio estabelecimento de relações que a CI possui com outras disciplinas pode ser verificado nas diversas 
conceituações que a CI tem recebido, algumas destas são identificadas por Robredo (2003, p. 55, 56), como a apresentada nas conferências do Georgia Institute of Technology (1961 e 1962), onde ocorreu a primeira formulação do conceito de CI e também na famosa conceituação apresentada por Borko, que afirma a CI se tratar de uma ciência interdisciplinar derivada e relacionada com vários campos.

Outro estudioso que tem a CI como uma ciência interdisciplinar é Saracevic (1996). Para ele a introdução da interdisciplinaridade na CI foi causada pelo grande número de profissionais de áreas diversas como a lingüística, engenharia, biblioteconomia, filosofia, psicologia e ciência da computação, que se ocuparam da resolução dos problemas informacionais que surgiram no contexto contemporâneo.

Do total de entrevistados, 93,5\% têm a CI como uma ciência interdisciplinar, e ao citarem exemplos de disciplinas que estabelecem relações com a CI, apareceram, com grande freqüência a administração, a biblioteconomia, a ciência da computação, a comunicação e a psicologia.

Para as 29 respostas dos entrevistados que identificam a CI como uma ciência interdisciplinar, foram criadas cinco categorias gerais de respostas que abarcassem a essência das justificativas apresentadas. Essas categorias e a freqüência em que aparecem por grupo estão dispostas na TAB. 2:

TABELA 2 - Justificativas dos entrevistados que disseram ser a CI uma ciência interdisciplinar

\begin{tabular}{|c|c|c|c|c|c|c|c|}
\hline \multirow[b]{2}{*}{ Categorias de respostas } & \multicolumn{6}{|c|}{ Grupos } & \multirow{2}{*}{ Total } \\
\hline & 1 & 2 & 3 & 4 & 5 & 6 & \\
\hline $\begin{array}{l}\text { Porque a CI recebe contribuições de outras } \\
\text { áreas do conhecimento }\end{array}$ & 1 & 2 & 2 & 3 & 3 & 1 & 12 \\
\hline $\begin{array}{l}\text { Porque a CI possui um diálogo com outras } \\
\text { ciências numa perspectiva de integração }\end{array}$ & 2 & 2 & - & - & 1 & 3 & 8 \\
\hline $\begin{array}{l}\text { Porque a CI necessita do conhecimento de } \\
\text { outras áreas para solucionar seus problemas }\end{array}$ & 2 & 1 & 1 & - & - & - & 4 \\
\hline Porque a CI já nasceu interdisciplinar & - & - & 2 & 1 & - & - & 3 \\
\hline Outros & - & 1 & - & - & - & 1 & 2 \\
\hline 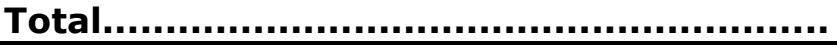 & 5 & 6 & 5 & 4 & 4 & 5 & 29 \\
\hline
\end{tabular}

Fonte: Dados da pesquisa.

Os grupos que forneceram respostas mais homogêneas foram os grupos 4 e 5. A heterogeneidade dos demais grupos pareceu relativamente igual.

A única justificativa que esteve presente em todos os grupos (41,3\% dos entrevistados a utilizaram), foi a de que a CI é interdisciplinar por receber contribuições de outras áreas do conhecimento. Essas contribuições dizem respeito à apropriação, pela CI, de concepções, práticas, métodos, pesquisas, teorias e produtos de diferentes áreas do conhecimento. Para um dos entrevistados, a CI se apropria desses conhecimentos para exercer a sua prática ou gerar novos conhecimentos. 
Para um outro entrevistado, enquanto ocorre essa apropriação a CI constrói seu próprio corpus de conhecimento e leis.

Já oito entrevistados $(27,5 \%)$ justificam que a CI é interdisciplinar por manter um diálogo com outras disciplinas numa perspectiva de integração, onde ocorre uma apropriação mútua de conhecimentos, concebendo uma relação de complementaridade. Esta justificativa é a que mais se aproxima da concepção de interdisciplinaridade tida por Pinto (2005, p. 154), onde a pesquisa interdisciplinar trabalha com uma diversidade de disciplinas que procuram "integrar os conceitos e metodologias, gerando um enriquecimento mútuo".

Uma outra justificativa apresentada para a caracterização interdisciplinar que a CI recebe é a de que ela necessita do conhecimento de outras áreas para solucionar os problemas de seu objeto de estudo, a informação - aproximadamente $13 \%$ dos entrevistados afirmam assim. Para os entrevistados a CI não sobreviveria se não mantivesse um relacionamento com outras disciplinas para estudar os fenômenos ligados a informação.

Dos entrevistados, três (10\%) acreditam que a CI já nasceu interdisciplinar, mas essa concepção, por duas vezes, foi acompanhada por outras justificativas, a que determina a interdisciplinaridade da CI por possuir um diálogo com outras disciplinas numa perspectiva de integração e outra que diz que a CI necessita do conhecimento de outras áreas para solucionar os problemas de seu objeto de estudo. Para um dos entrevistados a CI nasce através da fusão de duas disciplinas, a Biblioteconomia e a Documentação e continua se desenvolvendo ao estabelecer interlocuções com outras áreas. Outro entrevistado diz que a CI é interdisciplinar por natureza, conforme a já citada definição de Wersig de 1993.

As respostas enquadradas na categoria Outros não apresentaram nenhuma similaridade com as outras. Dentre elas houve a justificativa de que a CI é interdisciplinar por ser uma ciência social, pelo fato de a informação ser um produto que resulta das ações dos homens nela se encontra presente aspectos históricos, políticos, econômicos e sociais, torna-se necessário examinar a informação por diferentes focos.

Apenas dois entrevistados responderam que a CI não é interdisciplinar. Um dos argumentos utilizados foi de que a CI possui características próprias e que apenas em alguns momentos se apropria de princípios e conhecimentos de outras ciências. O outro aponta que a CI seria interdisciplinar apenas no seu discurso, que tentaria interagir com várias áreas, mas não conseguiria fazer relações totais, agindo de forma superficial. Essa dissidência relativa à interdisciplinaridade não é uma indagação exclusiva da CI, ela também é encontrada em discussões de outras áreas. Para França (2002), a interdisciplinaridade é um estado transitório, datado, pontual e relativo a um campo interdisciplinar. Entretanto, quando esse estado perdura e a troca de contribuições começa a deixar raízes e tradições, ela deixa seu estado interdisciplinar e dá origem a uma nova disciplina. Além disso, a autora questiona se o rótulo de interdisciplinaridade não estimula a falta de diálogo e interseção 
de contribuições, resultando na falta de especificidade do objeto de estudo.

\section{Uma ciência pós-moderna?}

A temática da pós-modernidade é um assunto que gera polêmica por várias razões, entre elas a possível sugestão de que, conforme Cardoso (1996), haveria uma ruptura na ordem anterior vigente (a modernidade) e sua substituição por outra. Existem muitas definições de pós-modernidade e elas dependem da linha de pensamento de cada autor. A visão mais comum é de que a pós-modernidade se refere a um período de grandes transformações sociais, culturais e tecnológicas que influenciaram o comportamento humano e a organização da sociedade. Um dos primeiros a tematizar a questão, Lyotard entende que o termo "designa o estado da cultura após as transformações que afetaram as regras dos jogos da ciência, da literatura e das artes a partir do final do século XIX" (CARDOSO, 1996, p. 67).

Diversas características, dissociadas do contexto da modernidade, têm sido apontadas como evidências de uma pós-modernidade, tais como a perda da confiança na razão, nas metanarrativas e no conhecimento científico tradicional, a interdisciplinaridade, a virtualização das relações humanas, a preocupação com os problemas ambientais, o consumismo, entre outros. Diversos autores, como Boaventura Santos, Edgar Morin e Fritjof Capra, têm postulado, então, a existência de uma nova forma de fazer ciência, ou o surgimento de um novo tipo de ciência, tida como pósmoderna.

No campo da CI, essa temática foi colocada de forma decisiva a partir de um artigo de Wersig, que a apresenta como uma ciência pósmoderna, por ter nascido exatamente no período de questionamento das ciências modernas e ter como tarefa a resolução de problemas causados pelas ciências modernas. A partir de então, a caracterização da CI como pós-moderna passou a ser um elemento sempre acionado nas tentativas de conceituação dessa disciplina.

Sendo assim a pesquisa requisitou dos entrevistados que dissessem se a CI é uma ciência pós-moderna. Os professores tiveram liberdade de responder segundo sua própria compreensão do que é pós-modernidade, o que gerou discussão sobre o assunto, dadas as diversas definições que eles utilizaram para avaliar a pergunta.

Dentre os 31 professores, 25 tomaram uma posição, afirmativa ou negativa, sobre a questão. Os restantes (sete entrevistados), preferiram não afirmar ser ou não a CI pós-moderna, isto é, não disseram nem que sim nem que não. Já entre os professores que tomaram partido na questão, 14 responderam que sim, a CI é uma ciência pós-moderna, e 10 responderam que não. A freqüência das respostas sim e não, bem como as justificativas para cada uma delas, separadas por categorias que exprimem sua idéia principal, seguem nas tabelas abaixo: 
TABELA 3 - Justificativas dos entrevistados que disseram ser a CI uma ciência pós-moderna.

\begin{tabular}{|c|c|c|c|c|c|c|c|}
\hline \multirow{2}{*}{ Categorias de respostas } & \multicolumn{6}{|c|}{ Grupos } & \multirow{2}{*}{ Tota } \\
\hline & 1 & 2 & 3 & 4 & 5 & 6 & \\
\hline $\begin{array}{l}\text { A CI é uma ciência que apresenta } \\
\text { características da pós-modernidade } \\
\text { A CI é um campo de conhecimento da } 2^{a}\end{array}$ & 2 & 1 & - & 2 & 1 & - & 6 \\
\hline $\begin{array}{l}\text { geração com aspectos de uma ciência pós- } \\
\text { moderna }\end{array}$ & 1 & 1 & - & - & 2 & 1 & 5 \\
\hline CI é uma ciência interdisciplinar & - & - & 1 & 1 & - & - & 2 \\
\hline Outros & - & - & - & 1 & - & - & 1 \\
\hline 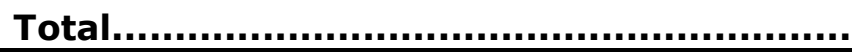 & 3 & 2 & 1 & 4 & 3 & 1 & 14 \\
\hline
\end{tabular}

Fonte: Dados da pesquisa.

TABELA 4 - Justificativas dos entrevistados que disseram não ser a CI uma ciência pós-moderna

\begin{tabular}{|c|c|c|c|c|c|c|c|}
\hline \multirow{2}{*}{ Categorias de respostas } & \multicolumn{6}{|c|}{ Grupos } & \multirow{2}{*}{ Total } \\
\hline & 1 & 2 & 3 & 4 & 5 & 6 & \\
\hline Não estamos na pós-modernidade & 2 & 1 & 1 & - & - & 1 & 5 \\
\hline $\begin{array}{l}\text { A CI existia antes, suas bases são antigas, ela } \\
\text { surge no séc XIX }\end{array}$ & - & - & 1 & 1 & 1 & 1 & 4 \\
\hline Outros & - & - & - & - & - & 1 & 1 \\
\hline 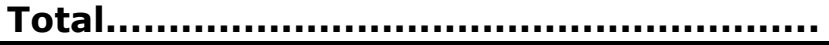 & 2 & 1 & 2 & 1 & 1 & 3 & 10 \\
\hline
\end{tabular}

Fonte: Dados da pesquisa.

Dos 14 entrevistados que responderam sim, seis (o que equivale a $43 \%$ ) acham que a CI possui características da pós-modernidade, destacando que ela surgiu no período da pós-modernidade. Outros cinco (36\%) destacaram que ela possui as características normalmente apontadas como características de uma ciência pós-moderna, tais como considerar o discurso epistemológico, reunir áreas de enfoque comum, sobrepor-se às disciplinas tradicionais e preocupar-se principalmente com o homem e com a sociedade.

Conforme Francelin, na pós-modernidade...

... os consensos teóricos se diluem, dando passagem à interdisciplinaridade, uma das principais marcas na construção do saber e figura marcante no debate sobre a legitimidade científica em finais do século XX (2004, p. 52).

Esse argumento embasa a resposta de dois professores (14\%), que asseguram que a CI é pós-moderna por ser interdisciplinar.

Dos 10 entrevistados que responderam não, alguns atentam que não estaríamos na pós-modernidade. Para alguns a pós-modernidade seria apenas um rótulo, ou seja, um modismo; para outros, a 
modernidade ainda nem se realizou completamente, o que inviabiliza pensar-se numa pós-modernidade; e há ainda quem não acredite na idéia de uma pós-modernidade, ponto de vista de dois professores.

Quatro entrevistados afirmam que a CI existia antes da pósmodernidade e que suas bases são antigas. Para eles, a CI está inserida em uma época anterior à pós-moderna, e, portanto, classificá-la como pós-moderna seria o mesmo que negar tudo o que foi realizado antes. Um entrevistado levantou ainda a questão de que a CI não existia de modo formalizado na época, mas na prática e na mente dos pensadores os problemas de que ela trata já eram abordados, evidenciando o ponto de vista de que os problemas trabalhados pela CI já eram pensados antes do período de vigência da pós-modernidade. Outro professor argumentou que a CI não é uma ciência pós-moderna, avaliando que ela se desenvolveu no século XX, porém fundamentada em diversas outras ciências modernas.

Curiosamente, um dos entrevistados considerou, segundo sua compreensão de pós-modernidade, que a CI é e não é uma ciência pósmoderna. Para a justificativa afirmativa ele acredita que a revolução da informação na época intensificou a importância das pesquisas na área; já para a negativa ele aponta que as bases da CI são antigas e datam de meados do século passado.

Os outros seis entrevistados que não tomaram posição definida sobre a questão disseram que o conceito de pós-modernidade é complexo, envolvido em contradições e duvidoso. Mesmo assim traçaram um paralelo entre o que eles concebem como pós-modernidade e sua relação com a CI. De acordo com um deles, a CI tenta ser uma ciência pósmoderna, mas ainda não consegue: "a CI será uma ciência pós-moderna se fundamentada em valores sociais evoluídos e buscar superar falhas da era moderna". Outro ressalta que "se coloca muito uma dimensão de pósmoderno para a CI como forma de apresentá-la no âmbito dos discursos competentes e de vanguarda". Os demais refletem que a CI pode ser pósmoderna por causa de seu nascimento, entretanto não demonstra claramente suas características. Um deles ressalta que "a CI é candidata ao título de ciência pós-moderna".

Pôde-se perceber que todos os grupos tiveram justificativas heterogêneas sobre a questão. O grupo 6, em que se observou maior quantidade de respostas "não", apresentou justificativas bem diferentes, e apenas uma resposta para cada. O grupo que se mostrou mais homogêneo foi o 1, tanto para as respostas "sim" como para as respostas não. Os grupos 2 e 3 não apresentaram nenhuma justificativa que tenha sido utilizada por mais de um professor.

\section{A relação entre a CI e a Biblioteconomia}

Desde seu surgimento como campo científico, em meados do século $X X$, a CI é alvo de questionamentos por parte dos estudiosos quanto ao seu grau de relação com a Biblioteconomia (ROBREDO, 2003). Entender o que é a CI já pode ser um dos fatores que gera dúvidas sobre suas semelhanças ou distinções com a library science. 
As práticas biblioteconômicas se iniciam muito antes da invenção da imprensa, tendo origem nas bibliotecas da Antiguidade. Mas a biblioteconomia-ciência só vem a tomar forma na década de 1930. Desde então, inúmeros foram os trabalhos e pesquisas voltados para a solução dos problemas de organização e acesso existentes em bibliotecas. Parecia fácil delimitar a área e os conceitos relacionados com a Biblioteconomia, mas essa visão passaria a chamar mais atenção a partir da formação do campo de estudo da CI.

As várias definições de CI a percebem de formas diferenciadas em suas relações com a Biblioteconomia. Dias (2000), por exemplo, argumenta que na verdade existe um grande campo denominado "biblioteconomia e ciência da informação". Já Saracevic (1996) define a CI como uma ciência interdisciplinar que dialoga, principalmente, com a Biblioteconomia, a Comunicação, a Computação e as Ciências Cognitivas. Por fim, Miksa propõe uma separação entre as duas disciplinas, apontando que, mesmo buscando solução para problemas iguais, a Biblioteconomia e a CI "representam campos científicos norteados por paradigma diferentes" (OLIVEIRA, 2005, p. 21). Nessa visão os dois campos podem ser vistos como trabalhos paralelos, que compartilham conhecimentos e práticas interdisciplinaridade - mas que nunca se encontram. E há, ainda, aqueles que traçam uma espécie de linha evolutiva, uma relação de continuidade, entre a Biblioteconomia e a CI, algumas vezes passando ainda, entre elas, pela documentação (ROBREDO, 2003; SILVA, RIBEIRO, 2002).

As discussões sobre a relação entre os dois campos ultrapassam o campo cientifico e geram questões no meio profissional e acadêmico. Como exemplo pode-se citar as mudanças que vêm ocorrendo nos nomes das instituições onde atuam os profissionais da informação. Na maioria dos casos é acrescentado e/ou trocado o nome dessas escolas, antes conhecidas pelo termo Biblioteconomia, para Ciência da Informação ou Biblioteconomia e Ciência da Informação. Segundo DIAS (2000, p. 70), quando instituições se denominam de tal forma "têm como objetivo oferecer ensino, pesquisa e extensão em toda amplitude do campo". No âmbito profissional o impasse ocorre devido à rejeição dos registros de profissionais pós-graduados em CI por parte dos conselhos de bibliotecários.

Pode-se observar, a partir das respostas apresentadas pelos professores da ECI, quando questionados sobre a relação entre CI e Biblioteconomia, que mesmo havendo uma minoria $(9,6 \%)$ que considera serem campos distintos todos os entrevistados acreditam que as duas áreas compartilham elementos comuns. A maior parte $(32,2 \%)$ enxerga os dois campos como tendo uma relação todo-parte, isto é, a CI englobaria a Biblioteconomia. Essa relação é muito bem aceita pelos profissionais aqui no Brasil, talvez por influência do Conselho Nacional de Desenvolvimento Científico e Tecnológico - CNPq, que classifica a Biblioteconomia como uma subárea da CI. A segunda resposta mais freqüente entre os entrevistados $(19,3 \%)$, é a argumentação de que a CI nasceu e se desenvolveu a partir da Biblioteconomia, podendo ser compreendida como uma evolução ou extensão desta. 
Houve ainda três tipos de respostas, cada uma acionada por quatro entrevistados $(12,9 \%)$ : uma que aponta para uma relação de interlocução e complementaridade entre as duas (sendo a CI a teoria e a Biblioteconomia a prática), outra que as descreve como áreas convergentes; e a última, em que os professores afirmam ser uma questão polêmica e pouco resolvida na literatura, sem terem uma posição definida. Os resultados gerais são apresentados a seguir, na TAB. 5:

TABELA 5 - Caracterizações do relacionamento entre a CI e a Biblioteconomia

\begin{tabular}{|c|c|c|c|c|c|c|c|}
\hline \multirow{2}{*}{ Categorias de respostas } & \multicolumn{6}{|c|}{ Grupos } & \multirow{2}{*}{ Total } \\
\hline & 1 & 2 & 3 & 4 & 5 & 6 & \\
\hline A Biblioteconomia faz parte da CI & 3 & 1 & 2 & - & 1 & 3 & 10 \\
\hline $\begin{array}{l}\text { A CI se desenvolve a partir das questões } \\
\text { tratadas na Biblioteconomia }\end{array}$ & - & 1 & 1 & 3 & 1 & - & 6 \\
\hline $\begin{array}{l}\text { São áreas complementares (uma é a teoria } \\
\text { e a outra a prática) }\end{array}$ & 2 & 1 & - & - & - & 1 & 4 \\
\hline $\begin{array}{l}\text { A CI e a Biblioteconomia são áreas } \\
\text { convergentes }\end{array}$ & - & 1 & 1 & 1 & - & 1 & 4 \\
\hline Acreditam que seja uma questão polêmica & 1 & 1 & - & 1 & 1 & - & 4 \\
\hline $\begin{array}{l}\text { São campos distintos com alguns elementos } \\
\text { em comum }\end{array}$ & - & 1 & 1 & - & 1 & - & 3 \\
\hline Total & 6 & 6 & 5 & 5 & 4 & 5 & 31 \\
\hline
\end{tabular}

Fonte: Dados da pesquisa.

Observa-se que os grupos mais heterogêneos em relação às respostas foram os grupos 2 e 5 , nos quais cada professor apresentou uma resposta diferente. Já o grupo mais homogêneo foi o 6 , em que mais da metade dos entrevistados deram a mesma resposta. Também merece destaque a maior incidência da justificativa a CI se desenvolve a partir das questões da Biblioteconomia entre os membros do grupo 4.

\section{Os autores mais relevantes}

A literatura de história e filosofia da ciência (OMNÉS, 1996; ALFONSO-GOLDFARB, 1994; ROSSI, 2001) sempre destacou a importância dos clássicos, isto é, dos autores tidos como fundamentais, basilares, de uma disciplina científica. Um critério que aponta o amadurecimento e a consolidação de uma ciência é o grau de consenso com que seus autores mais relevantes são reconhecidos pelos praticantes dessa ciência.

No caso da CI, o grau de consenso é baixíssimo (ALMEIDA, 2005), existindo mesmo grande desconhecimento e visões contraditórias (DIAS, 2000). Na área não existe até hoje um manual introdutório consistente ou uma identificação estável de escolas e teorias. Isso se reflete, por extensão, na dificuldade em se estabelecer os autores mais relevantes. 
Solicitados a apontar até dez autores considerados os mais relevantes da área de $\mathrm{CI}$, os entrevistados se depararam com alguns questionamentos, tais como: relacionar autores nacionais ou estrangeiros; autores antigos ou contemporâneos; autores relevantes para toda a área de informação ou apenas para subáreas (tais como gestão, catalogação, etc). Contudo, eles não foram orientados quanto a isso, de forma que cada entrevistado interpretou a pergunta como quis. Os 31 professores entrevistados apontaram 107 autores, o que aponta uma imensa variedade. Destes, 62 receberam apenas uma citação. Outros 30 receberam apenas duas (21 autores) e três (9 autores) citações. Os autores mais citados (com pelo menos quatro citações) são apresentados a seguir, na TAB. 6:

TABELA 6 - Autores mais citados como relevantes na CI

\begin{tabular}{|c|c|c|c|c|c|c|c|}
\hline \multirow{2}{*}{1 Autores } & \multicolumn{6}{|c|}{ Grupos } & \multirow{2}{*}{ Total } \\
\hline & 1 & 2 & 3 & 4 & 5 & 6 & \\
\hline Saracevic & 3 & 1 & 1 & 2 & 3 & 2 & 12 \\
\hline Le Coadic & 1 & 1 & 1 & 1 & 3 & 3 & 10 \\
\hline Choo & 4 & 0 & 2 & 0 & 2 & 2 & 10 \\
\hline Shera & 1 & 1 & 3 & 3 & 0 & 1 & 9 \\
\hline González de Gómez & 3 & 1 & 1 & 1 & 0 & 1 & 7 \\
\hline Lancaster & 1 & 0 & 2 & 2 & 0 & 2 & 7 \\
\hline Wersig & 1 & 1 & 2 & 2 & 0 & 0 & 6 \\
\hline Buckland & 1 & 1 & 3 & 0 & 0 & 1 & 6 \\
\hline Capurro & 1 & 1 & 0 & 2 & 0 & 2 & 6 \\
\hline Barreto & 2 & 3 & 0 & 0 & 0 & 1 & 6 \\
\hline Kulhthau & 1 & 0 & 1 & 2 & 0 & 1 & 5 \\
\hline Dervin & 2 & 0 & 1 & 0 & 1 & 2 & 5 \\
\hline Hjorland & 2 & 1 & 2 & 0 & 0 & 0 & 5 \\
\hline Borko & 2 & 0 & 1 & 2 & 0 & 0 & 5 \\
\hline Ranganathan & 0 & 0 & 3 & 1 & 0 & 0 & 4 \\
\hline Autores com 3 citações & & & & & & & 27 \\
\hline Autores com 2 citações & & & & & & & 42 \\
\hline Autores com 1 citação & & & & & & & 62 \\
\hline Total de citações & & & & & & & 234 \\
\hline
\end{tabular}

Fonte: Dados da pesquisa.

O autor mais citado, Saracevic, foi identificado por apenas 12 entrevistados, isto é, $38,7 \%$ dos entrevistados, como um dos dez autores mais relevantes da área - o que significa que não houve autor que tenha sido identificado por pelo menos metade dos entrevistados. Os autores que vêm logo a seguir, Le Coadic e Choo, foram apontados por menos de um terço $(32,2 \%)$ dos entrevistados. Além disso, apenas dois autores foram citados por professores de todos os grupos.

No total foram registradas 234 citações a autores (o que dá uma média de 7,54 citações por entrevistado). O grau de dispersão foi tão grande que os dez autores mais citados (para uma pergunta que pedia os dez autores mais relevantes) somam apenas 79 citações, o que equivale a pouco mais de um terço $(33,76 \%)$ das citações feitas. 
Entre os 15 autores mais citados, destaca-se a imensa maioria de estrangeiros - 13 no total. Há apenas dois autores nacionais, sendo um deles na verdade estrangeiro, mas com carreira no Brasil. Entre os estrangeiros citados destacam-se aqueles que já estiveram no Brasil para eventos, palestras ou orientações, tais como Saracevic, Dervin, Capurro, Choo.

Quase todos também são pesquisadores contemporâneos, isto é, com relevante produção científica nas décadas de 1990 e atual. Alguns deles, ainda que continuem atuantes, possuem trabalhos relevantes desde a década de 1960, como é o caso de Lancaster. Apenas Shera, Borko e Ranganathan são autores mais antigos, com produção em meados do século $X X$. Também pode-se perceber a presença de muitos pesquisadores que atuaram como conferencistas no evento internacional de conceitos em CI ocorrido em Tampere, em 1991, tais como Saracevic, Buckland e Wersig.

As temáticas de trabalho dos autores mais citados também estão mais relacionadas com questões epistemológicas da CI como um todo. Esse é o caso de Saracevic, Le Coadic, Shera, González de Gómez e Wersig, entre outros. Autores que tratam de questões mais específicas, tais como Choo (gestão do conhecimento), Lancaster (avaliação de bibliotecas), Kuhlthau (aprendizagem em bibliotecas escolares) e Dervin (estudos de usuário) registraram, contudo, significativa presença.

Em relação às variações pelos grupos, pode-se perceber certas tendências. Os grupos 5 e 6 , formados por professores com menos homogeneidade entre si, apresentaram as maiores freqüências para os três autores mais citados (Saracevic, Le Coadic e Choo). Alguns autores citados tiveram participação mais uniforme pelos grupos (Saracevic, Le Coadic, González de Gómez, Kuhlthau) enquanto outros apresentaram maiores discrepâncias e presença mais significativa em algum grupo específico (por exemplo, Choo no grupo 1, Barreto no grupo 2, Shera nos grupos 3 e 4, Buckland e Ranganathan no grupo 3). Contudo, o que se pôde perceber é que, mesmo dentro dos grupos mais homogêneos, em que os professores estão unidos numa linha ou grupo de pesquisa, ainda há grande dispersão no que se refere à identificação de autores mais relevantes.

\section{Os trabalhos mais relevantes}

A mesma dificuldade em se estabelecer os autores mais importantes da área também é encontrada ao se estabelecer as obras mais relevantes. Os entrevistados foram solicitados a indicar os dez trabalhos mais relevantes para a área de CI. Nestes trabalhos poderiam se incluir livros, artigos, trabalhos apresentados em congressos, capítulos de livros etc. Esta questão foi a que teve o maior grau de abstenção: obteve-se apenas 153 citações, cerca de $49 \%$ do que era esperado. Foram poucos os entrevistados que chegaram a citar os dez trabalhos; outros, nem mesmo chegaram a citar um. 
Também foi observada grande heterogeneidade entre as citações. Foram 91 os trabalhos que obtiveram uma citação e 22 que chegaram a pelo menos duas citações, sendo $13 \mathrm{com}$ duas citações, cinco com três citações, um com quatro citações, dois com cinco citações e um com sete citações, somando 62 citações. Os trabalhos mais citados se encontram na TAB. 7:

TABELA 7 - Trabalhos mais citados como relevantes na CI

\begin{tabular}{|c|c|c|c|c|c|c|c|c|}
\hline \multirow{2}{*}{ Trabalhos } & \multirow{2}{*}{ Tipo } & \multicolumn{6}{|c|}{ Grupos } & \multirow{2}{*}{ Total } \\
\hline & & 1 & 2 & 3 & 4 & 5 & 6 & \\
\hline A ciência da informação - Le Coadic & $\bar{L}$ & 1 & 1 & - & 2 & 2 & 1 & 7 \\
\hline Organização do conhecimento - Choo & L & 1 & - & - & - & 2 & 2 & 5 \\
\hline Sociedade em rede - Manuel Castells & L & 2 & - & - & - & 1 & 2 & 5 \\
\hline $\begin{array}{l}\text { Information needs and uses - } \\
\text { Dervin/Nilan }\end{array}$ & A & 1 & - & 1 & - & 1 & 1 & 4 \\
\hline $\begin{array}{l}\text { Prolegomena to library classification - } \\
\text { Ranganathan }\end{array}$ & L & - & - & 3 & - & - & - & 3 \\
\hline Information retrieval today - Lancaster & A & 1 & - & 2 & - & - & - & 3 \\
\hline $\begin{array}{l}\text { A abordagem temática da informação - } \\
\text { Foskett }\end{array}$ & $\mathrm{L}$ & - & - & 2 & - & - & 1 & 3 \\
\hline $\begin{array}{l}\text { Ecologia da informação - Davenport } \\
\text { A árvore do conhecimento: as bases }\end{array}$ & L & 2 & - & - & - & - & 1 & 3 \\
\hline $\begin{array}{l}\text { biológicas para a compreensão humana } \\
\text { - Maturana }\end{array}$ & L & 1 & - & - & - & 2 & - & 3 \\
\hline $\begin{array}{l}\text { Information science: the study of post- } \\
\text { modern knowledge usage - Wersig }\end{array}$ & A & - & 1 & 1 & - & - & - & 2 \\
\hline $\begin{array}{l}\text { The phenomena of interest of } \\
\text { information science - Wersig/ Nevelling }\end{array}$ & A & - & - & 1 & 1 & - & - & 2 \\
\hline $\begin{array}{l}\text { Introduction to information science - } \\
\text { Saracevic }\end{array}$ & L & - & - & 1 & 1 & - & - & 2 \\
\hline $\begin{array}{l}\text { Information science: origin, evolution } \\
\text { and relations - Saracevic }\end{array}$ & $\mathrm{T}$ & - & - & 1 & - & 1 & - & 2 \\
\hline Cibercultura - Lévy & L & - & - & - & - & 2 & - & 2 \\
\hline $\begin{array}{l}\text { Gestão da informação e do } \\
\text { conhecimento - Paim (Org.) }\end{array}$ & L & 2 & - & - & - & - & - & 2 \\
\hline $\begin{array}{l}\text { Criação de conhecimento na empresa - } \\
\text { Nonaka/ Takeuchi. }\end{array}$ & L & 1 & - & - & - & 1 & - & 2 \\
\hline $\begin{array}{l}\text { Conhecimento e sociedade: } \\
\text { pressupostos da antropologia da } \\
\text { informação - Marteleto }\end{array}$ & C & - & 1 & - & - & - & 1 & 2 \\
\hline $\begin{array}{l}\text { Indexação e resumos: teoria e pratica - } \\
\text { Lancaster }\end{array}$ & L & - & - & 1 & 1 & - & - & 2 \\
\hline $\begin{array}{l}\text { Epistemologia e ciência da informação - } \\
\text { Capurro }\end{array}$ & $\mathrm{T}$ & - & 1 & - & - & - & 1 & 2 \\
\hline As we may think - Bush & L & 1 & - & 1 & - & - & - & 2 \\
\hline Information as a thing - Buckland & $A$ & - & - & 2 & - & - & - & 2 \\
\hline Information Science: what is it? - Borko & A & - & - & 1 & 1 & - & - & 2 \\
\hline Obras com 1 citação & - & 6 & 13 & 22 & 25 & 9 & 16 & 91 \\
\hline Total de citações & & 19 & 17 & 39 & 31 & 21 & 26 & 153 \\
\hline
\end{tabular}

Fonte: Dados da pesquisa.

NOTA: Os símbolos contidos na coluna Tipo correspondem: $\mathrm{A}=$ artigo; $\mathrm{C}=$ capítulo de livro; $\mathrm{L}=$ livro; $\mathrm{T}$ = trabalho apresentado em congresso. 
Os grupos que apresentaram maior homogeneidade foram os grupos 1,5 e 6 . As quatro obras mais citadas foram, em sua maioria, apontadas por estes grupos. Os grupos 1 e 5 foram os que os trabalhos tiveram maior nível de aproveitamento. Do grupo 1, cerca de $68 \%$ e do grupo 5, cerca $57 \%$ dos trabalhos apareceram por mais de duas vezes.

Devido à grande variedade de obras citadas, e à pouca concordância entre os entrevistados, ficou claro que não existe uma obra considerada como a mais importante para a área. O trabalho mais citado, o livro $A$ Ciência da Informação de Le Coadic, obteve apenas sete identificações, isto é, $22,6 \%$ dos entrevistados o citaram.

Outro fator constatado é a influência da área de atuação ao citarem os trabalhos, em que alguns aparecem com freqüência em grupos específicos. Este é o caso do grupo 3, onde três entrevistados indicaram a obra Prolegomena to Library Classification e o grupo 1, onde dois entrevistados indicaram a obra Gestão do Conhecimento e da Informação.

Le Coadic, Choo e Dervin são autores de trabalhos que também apareceram com freqüência entre os autores mais citados na pesquisa. A relação entre os autores mais citados e os trabalhos mais citados foi expressiva, apenas quatro dos autores mais citados não foram indicados com seus trabalhos. Contudo, Saracevic, autor mais citado, obteve dois trabalhos que apresentaram mais de uma citação, além de outro trabalho com uma citação.

Além da baixa representatividade de autores nacionais, verificou-se que a década de 1990 apresentou grande relevância nas publicações mais citadas pelos entrevistados - as publicações desta década representaram $50 \%$ do total, evidenciando o caráter de "disciplina científica recente" (OLIVEIRA, 2005. p. 13) que a CI possui.

\section{Apontamentos finais}

O conjunto dos dados encontrados é muito rico e pode proporcionar ainda um detalhamento que não cabe nos limites deste texto. Além do somatório geral das respostas, que permite traçar um mapa destas questões conforme a concepção dos professores da ECI/UFMG, há ainda a riqueza das respostas dadas, das argumentações utilizadas, das referências apresentadas.

Além disso, por ter como universo um conjunto de professores de uma mesma instituição, a pesquisa pôde relacionar a posição de cada professor com seu pertencimento em termos de temáticas de pesquisa e características de formação acadêmica e teórica. Tal fato é particularmente relevante no caso da $\mathrm{CI}$, que é uma área na qual grande parte dos pesquisadores são provenientes de outras áreas - em 1999, $45,5 \%$ dos pesquisadores da área tinham titulação de outra área que não a CI, e esse número caiu ligeiramente, para 43,7\%, em 2006 (NORONHA; FUJINO, 2006, p. 3).

Os dados analisados ao longo do trabalho mostraram questões sobre as quais existe uma concordância maior (dos 31 entrevistados, 30 acreditam ser a CI uma ciência social, e 29 acreditam que ela seja uma 
ciência interdisciplinar) e outras sobre as quais há grandes discordâncias (como no caso de ser uma ciência pós-moderna, com a qual 14 concordam e 10 discordam, ou a respeito do tipo de relação estabelecida entre a biblioteconomia e a $\mathrm{CI}$, em que foram encontradas seis categorias diferentes de respostas). Em todas elas, contudo, pôde-se perceber entendimentos muito discrepantes sobre o significado das categorias perguntadas (o que significa mesmo ser uma ciência social? O que é interdisciplinaridade?), ponto que aliás foi ressaltado por quase todos os entrevistados: tratam-se de questões mal resolvidas da área como um todo.

Este trabalho levanta uma série de questões essenciais para a área e, ao promover um mapeamento das compreensões sobre essas questões, pretende contribuir na consolidação da área de CI no Brasil, tarefa que, para ser executada, terá de passar, certamente, pela consideração dos aspectos humanos envolvidos, isto é, das compreensões específicas daqueles que vêm atuando na área e, com essa atuação, construindo-a da maneira como ela existe hoje.

\section{Referências}

ALFONSO-GOLDFARB, Ana Maria. O que é história da ciência. São Paulo: Brasiliense, 1994.

ALMEIDA, Carlos. O campo da ciência da informação: suas representações no discurso coletivo dos pesquisadores do campo no Brasil. 2005. Dissertação (Mestrado em Ciência da Informação) - CCE/UFSC, Florianópolis, 2005.

ALVARENGA, Lídia. Bibliometria e arqueologia do saber de Michel Foucault: traços de identidade teórico-metodológica. Ciência da Informação, Brasília, v. 27, n. 3, p. 253-261, set./dez. 1998.

BOURDIEU, Pierre. O campo científico. In: ORTIZ, R. (Org.). Pierre Bourdieu: sociologia. São Paulo: Ática, 1983.

CAPURRO, Rafael. Epistemologia e ciência da informação. In: ENCONTRO NACIONAL DE PESQUISA EM CIÊNCIA DA INFORMAÇÃO, 5, 2003, Belo Horizonte. Anais... Belo Horizonte: Associação Nacional de Pesquisa e PósGraduação em Ciência da Informação e Biblioteconomia, 2003. 1 CD-ROM.

CARDOSO, Ana Maria. Pós-Modernidade e informação: conceitos complementares? Perspectivas em Ciência da Informação, Belo Horizonte, v. 1, n. 1, p. 63-79, jan/jul. 1996.

DIAS, Eduardo Wense. Biblioteconomia e ciência da informação: natureza e relações. Perspectivas em Ciência da Informação, Belo Horizonte, v. 5, p. 11-15, jan./jun. 2000. Número especial.

ELLIS, David. Paradigms and proto-paradigms in information retrieval research. In: VAKKARI, P.; CRONIN, B. (Eds.). Conceptions of library and information science: historical, empirical and theoretical perspectives. Londres, Los Angeles: Taylor Graham, 1992. p. 165-186. 
FRANÇA, Vera Veiga. Paradigmas da comunicação: conhecer o quê? In: MOTTA, L. G. et al. (orgs). Estratégias e culturas da comunicação. Brasília: Ed. da UnB, 2002. p. 13-29.

FRANCELIN, Marivalde Moacir. Configuração epistemológica da ciência da informação no Brasil em uma perspectiva pós-moderna: análise de periódicos da área. Ciência da Informação, Brasília, v.33, n.2, 2004.

GRESSLER, Lori. Introdução à pesquisa: projetos e relatórios. São Paulo: Loyola, 2003.

HOCHMAN, Gilberto. A ciência entre a comunidade e o mercado: leituras de Kuhn, Bourdieu, Latour e Knorr-Cetina. In: PORTOCARRERO, V. (Org.). Filosofia, história e sociologia das ciências: abordagens contemporâneas. Rio de Janeiro: Fiocruz, 1994.

MIKSA, Francis. Library and information science: two paradigms. In: VAKKARI, P.; CRONIN, B. (Eds.). Conceptions of library and information science: historical, empirical and theoretical perspectives. Londres, Los Angeles: Taylor Graham, 1992. p. 229-252.

NORONHA, Daisy; FUJINO, Asa. Teses e dissertações em ciência da informação: a multidisciplinaridade não revelada na avaliação da produção científica. In: ENCONTRO NACIONAL DE PESQUISA EM CIÊNCIA DA INFORMAÇÃO, 7., 2006, Marília. Anais... Marília: Associação Nacional de Pesquisa e Pós-Graduação em Ciência da Informação, 2006. 1 CD-ROM.

OLIVEIRA, Marlene (Org.). Ciência da informação e biblioteconomia: novos conteúdos e espaços de atuação. Belo Horizonte: Ed. UFMG, 2005. p. 9-28.

OMNĖS, Roland. Filosofia da ciência contemporânea. São Paulo: Unesp, 1996.

PINTO, Paulo. A lógica contemporânea e a transdisciplinaridade. In: DOMINGUES, I. Conhecimento e transdisciplinaridade 2. Belo Horizonte: Ed. UFMG, 2005. p. 137-167.

ROBREDO, Jaime. Da ciência da informação revisitada aos sistemas humanos de informação. Brasília: Thesaurus; SSRR Informações, 2003.

ROSSI, Paolo. O nascimento da ciência moderna na Europa. Bauru: Edusc, 2001.

SARACEVIC, Tefko. Ciência da informação: origem, evolução e relações. Perspectivas em Ciência da Informação, Belo Horizonte, v. 1, n. 1, p. 4162, jan./jun. 1996.

SILVA, Edna Lúcia. A construção do conhecimento científico: o processo, a atividade e a comunicação científica em um laboratório de pesquisa. Perspectivas em Ciência da Informação, Belo Horizonte, v. 7, n. 2, p. 109125, jul./dez. 2002. 
SILVA, Armando; RIBEIRO, Fernanda. Das "ciências" documentais à ciência da informação: ensaio epistemológico para um novo modelo curricular. Porto: Afrontamento, 2002. 